\title{
Relationships between Hypothalamic Catecholamines, Blood Pressure and Body Temperature in Spontaneously Hypertensive Rats
}

\author{
Yoshiaki Isobe, Kokichi OHARA, Mitsuo KosaKa,* \\ and Kyuzo AOKI** \\ Department of Physiology and ${ }^{* *}$ Department of Internal Medicine, Nagoya \\ City University Medical School, Nagoya, 467 Japan \\ *Department of Epidemiology, Institute for Tropical Medicine, \\ Nagasaki University, Nagasaki, 852 Japan
}

\begin{abstract}
Summary Rectal temperature, catecholamine contents in the hypothalamus, and blood pressure were measured in spontaneously hypertensive rats (SHR) and normotensive Wistar-Kyoto rats (WKY). SHR had a significantly higher rectal temperature than WKY. Noradrenaline contents were lower in SHR than WKY. Noradrenaline was inversely correlated with the blood pressure and body temperature in SHR. In subgroups of SHR, differences in values of the parameters mentioned above were also observed.
\end{abstract}

Many reports have been made concerning the regulatory role of catecholamines in the brain. It has been suggested that body temperature and blood pressure are regulated by the catecholamines in the hypothalamus. However, relationships between body temperature, blood pressure and hypothalamic catecholamines have not been fully elucidated. The present investigation examines possible correlations between body temperature regulation, the concentration of catecholamines in the hypothalamus, and blood pressure.

Spontaneously hypertensive rats (SHR, Oкамото and AoKI, 1963) and normotensive Wistar-Kyoto rats (WKY, which have the same ancestral origin as SHR) were supplied from Kyoto University. SHR were maintained by inbreeding in our laboratory up to the $F_{7}$ generation. Male $S H R$ of $F_{6}$ or $F_{7}$ (Fig. 1) were used from the age of 14 weeks, and corresponding age-matched WKY were used as the control. Classification of subgroups of $\mathrm{H}_{1}, \mathrm{H}_{2}$ and $\mathrm{H}_{3}$ of SHR are outlined in Fig. 1. All the rats were caged in groups. They were housed at least 2 weeks before use in an air-conditioned room at $24 \pm 1^{\circ} \mathrm{C}$, and fed food and water ad libitum.

Received for publication May 9, 1980

磯部芳明, 大原孝吉, 小坂光男, 青木久三 


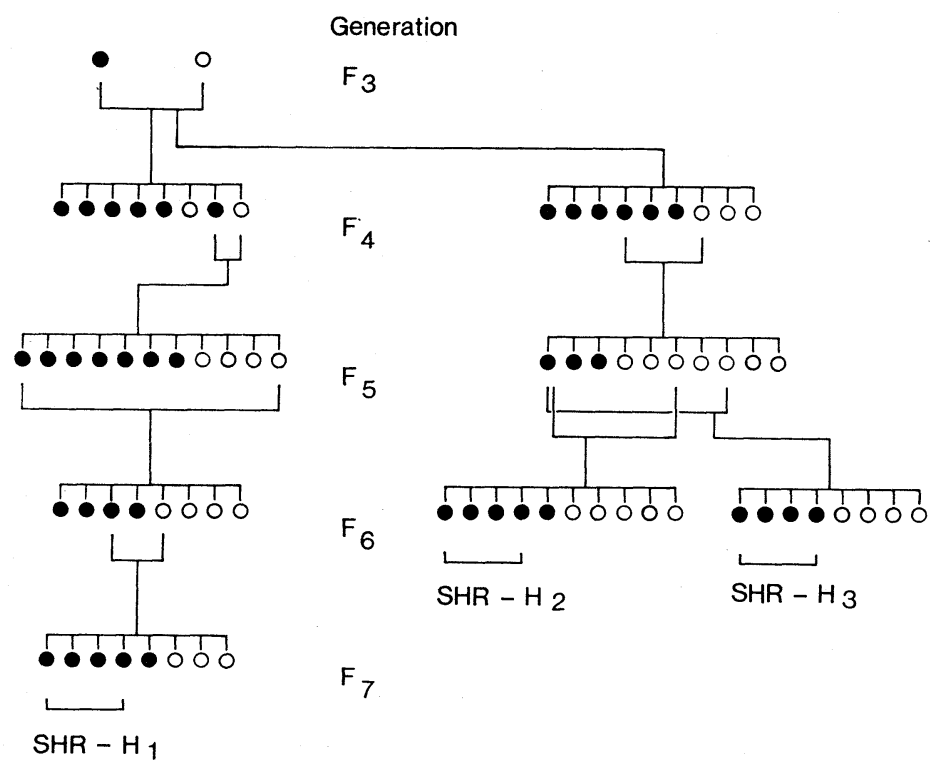

Fig. 1. Pedigree of a strain of spontaneously hypertensive rats $\left(F_{3}-F_{6}\right.$ or $\left.F_{3}-F_{7}\right)$. Each subgroup corresponds to the subgroups presented in Table 1. Closed circles and open circles represent male and female rats, respectively.

All measurements were performed at a definite time of day (10:00 AM12: $00 \mathrm{AM})$. The animals were well trained for measurement.

Systolic blood pressure was measured in an unanesthetized condition 3 times in a day for 3 consecutive days by means of a tail-plethysmograph. Three recordings a day were taken at approximately 1-min intervals under resting conditions. Variation among the 9 recordings in the same rat was less than $\pm 4 \mathrm{mmHg}$. The values obtained over the 3-day period were averaged for each rat, according to the method of Окамото and AoKi (1963), and the mean value (mean \pm SD) for each subgroup was calculated. Rectal temperature was measured in an unrestrained condition by a thermistor thermometer, inserted $5 \mathrm{~cm}$ from the anal sphinctor, once a day for 37 days. Internal variations in the same rat did not exceed $\pm 0.12^{\circ} \mathrm{C}$, calculated from the 37 measurements. The average of these temperature values were calculated for each rat, and subsequently the mean of each group was obtained. After these measurements were completed, rats were sacrificed at 19 or 20 weeks of age by decapitation, and their brains were rapidly removed and placed on a glass plate on ice. The hypothalamus was dissected and weighed according to the method of GLOwINSKI and IVERSEN (1966), and then homogenized. Noradrenaline and adrenaline were extracted by alumina absorption method and assayed by the method of Crout (1961). The recovery rates of catecholamines were $75-80 \%$, and the reliability of this procedure is ensured by 


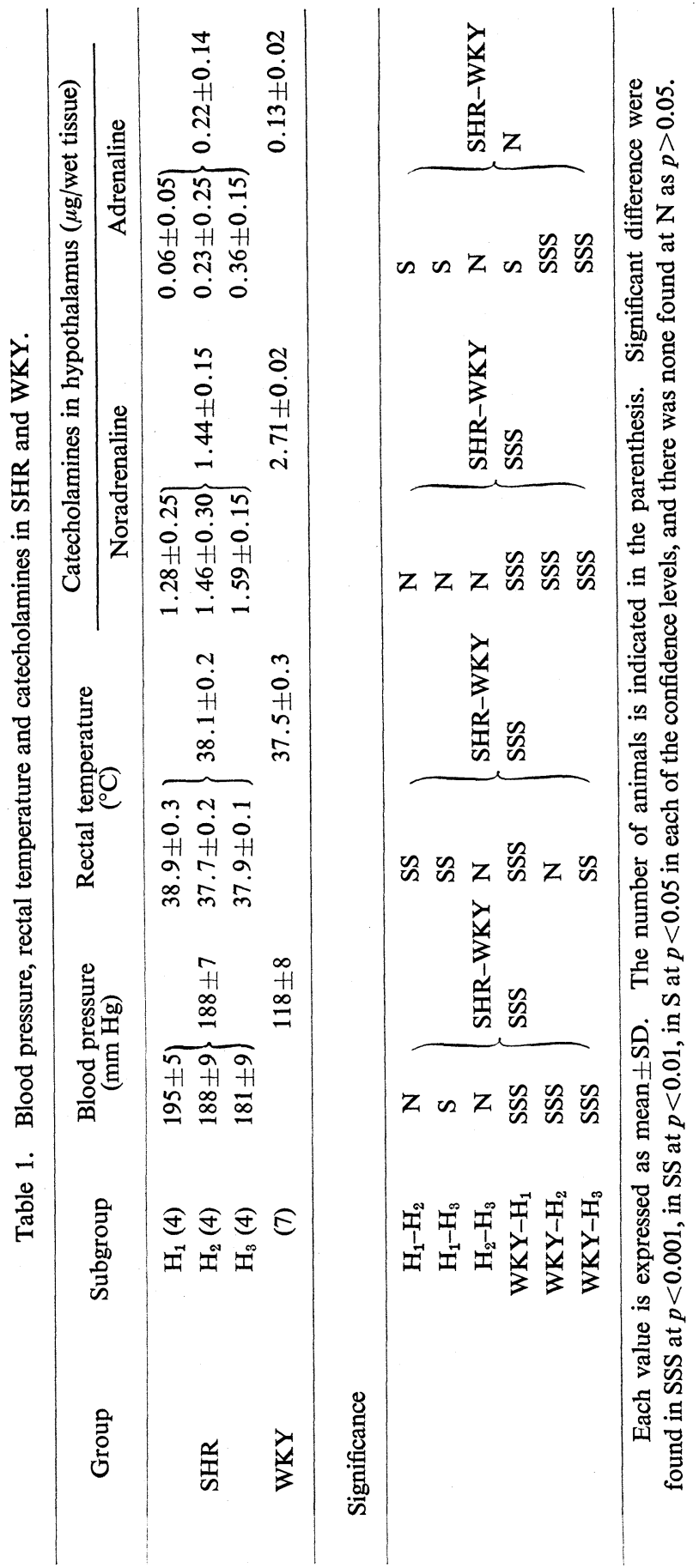


having a variation of $\pm 0.05 \mu \mathrm{g}$ of noradrenaline and adrenaline per $1 \mathrm{~g}$ wet tissue of hypothalamus.

Statistical analysis of the data was done by the Student's $t$-test.

All the results obtained are summarized in Table 1. Blood pressure of SHR was approximately $60 \%$ higher than WKY $(p<0.001)$. Among subgroups of SHR, $\mathrm{H}_{1}$ showed higher blood pressure than $\mathrm{H}_{3}\left(p<0.05\right.$, significantly) as well as $\mathrm{H}_{2}$ (not significant). The average rectal temperature of all SHR was about $0.6^{\circ} \mathrm{C}$ higher than WKY $(p<0.001)$. The result agrees well with those in the previous report which showed a higher rectal temperature of about $1{ }^{\circ} \mathrm{C}$ in SHR than that in WKY and suggested an elevated thermoregulatory set-point in SHR (WILSON et al., 1977).

The concentration of noradrenaline was significantly lower in the hypothalamus $(p<0.001)$. The adrenaline concentration in the hypothalamus differed between the SHR subgroups, but as a whole, the SHR groups were slightly higher when compared with the WKY, although this was not statistically significant. The different concentration of adrenaline in the $\mathrm{H}_{1}$ subgroup as compared with other subgroups of SHR, might be considered to be due to the insufficiency of the turnover step from noradrenaline to adrenaline, since the noradrenaline concentration did not differ in subgroups of SHR. However, it has been reported that phenylethanolamine- $N$-methyl transferase which catalyzes this step did not differ between SHR and WKY (Gianutsos and Moore, 1978). Beside this, no correlation was found in the present study between blood pressure and concentration of adrenaline which was analyzed in SHR $(r=0.35)$. Thus, the differences in adrenaline concentration in subgroups of SHR might be caused by 1 ) the differences in deposition step which was catalyzed by catechol-o-methyl transferase or monoamine oxidase in subgroups of SHR, 2) the different system which control blood pressure and body temperature, 3) the differences in the family line of SHR including the occasion of 1) and 2). However, it will be a further problem to clarify these relations. A lower noradrenaline content in the hypothalamus of SHR was previously reported by YAMORI et al. (1970), and this agrees with the results of the present study. On the other hand, GianUTSOs and MoORE (1978) reported that the concentration of epinephrine, but not noradrenaline, was higher in the hypothalamus of SHR. NAGAOKA and LOVENBERG (1977) have reported that the aminergic biosynthesizing enzymes of tyrosine hydroxylase and dopamine$\beta$-hydroxylase were higher in the hypothalamus of SHR, and they showed a significant correlation of dopamine- $\beta$-hydroxylase activity with blood pressure in SHR. It was also suggested by the present study that the noradrenaline concentration is inversely correlated with blood pressure $(r=-0.87)$ and body temperature $(r=$ $-0.65)$, but there were no significant correlations in adrenaline concentration with the other parameter. The results on noradrenaline levels contradict the report of Gianutsos and Moore (1978). The discrepancies may be explained by the following two reasons: 1) The technical difficulties in dissecting the hypothalamus, 
even though the same method was used by GLOWINSKI and IVERSEN (1966), might have caused different results because of unequal distribution of catecholamines in hypothalamus as pointed out by VersteEg et al. (1976). 2) Differences in the family line of animals, although SHR of the same origin were used in the two studies. Concerning the differences of the family line, it was seen in the present study for example, that only the $\mathrm{H}_{2}$ subgroup showed no significant difference in body temperature as compared with WKY, although noradrenaline concentration in the hypothalamus was on average lower in all the subgroups $\left(\mathrm{H}_{1}, \mathrm{H}_{2}\right.$ and $\mathrm{H}_{3}$, see Table 1).

The body temperature was higher in SHR than WKY in this study. It has also been reported that SHR are more susceptible to heat stress than WKY (Wright and KNECHT, 1977). Since no obvious differences in metabolic rate between SHR and WKY were found (WILSON et al., 1977), the increased susceptibility to thermal stress may be due to impaired heat dissipation from the body surface, mostly from the tail. Retardation of heat loss from the vessel will be supposed from the observation of IRIUCHIJMA (1973), who mentioned that circulatory resistance is higher in SHR. One of the authors reported that resistance to heat is greater when the concentration of noradrenaline in the hypothalamus is higher (IsOBE, 1976). It was suggested that noradrenaline in the hypothalamus generally tends to reduce the body temperature in rats (BLIGH, 1973). These findings suggest that catecholamines in the hypothalamus are closely related to the regulation of body temperature and blood pressure, although the relationship seems to be different among the family line of SHR.

\section{REFERENCES}

Bligh, J. (1973) Central transmitter substances and thermoregulation. In: Temperature Regulation in Mammals and Other Vertebrates, Vol. 30, ed. by NeUBERGER, A. and TATUM, L. L. North-Holland Publ. Co., Amsterdam, Netherlands, pp. 133-152.

Crout, J. R. (1961) Catechol amines in urine. In: Standard Methods of Clinical Chemistry, Vol. 3, ed. by Seligson, D. Academic Press, Inc., New York, pp. 62-80.

Gianutsos, G. and Moore, E. (1978) Epinephrine contents of sympathetic ganglia and brain regions of spontaneously hypertensive rats of different ages. Proc. Soc. Exp. Biol. Med., 158: 45-49.

GlowinsKi, J. and IVERSEN, L. L. (1966) Regional studies of catecholamines in the rat brainI. The disposition of $\left[{ }^{3} \mathrm{H}\right]$ norepinephrine, $\left[{ }^{3} \mathrm{H}\right]$ dopamine and $\left[{ }^{3} \mathrm{H}\right]$ dopa in various regions of the brain. J. Neurochem., 13: 655-669.

IRIUCHIJIMA, J. (1973) Cardiac output and total peripheral resistance in spontaneously hypertensive rats. Jpn. Heart J., 14: 267-272.

IsoBE, Y. (1976) Effect of thermal stress as well as heat and cold adaptation on catecholamines in hypothalamus of rats. J. Nagoya City Med. Assoc., 26: 499-514 (in Japanese).

NAGAOKA, A. and LovenberG, W. (1977) Regional changes in the activities of aminergic biosynthetic enzymes in the brains of hypertensive rats. Eur. J. Pharmacol., 43: 297-306.

Окамото, K. and AoKI, K. (1963) Development of a strain of spontaneously hypertensive rats. Jpn. Circ. J., 27: 282-293.

Vol. 30, No. 5, 1980 
Versteeg, D. G., Palkovits, M., Gugten, J., Wijnen, H. J. M., Smeets, G. W. M., and Jong, W. (1976) Catecholamine content of individual brain regions of spontaneously hypertensive rats (SH-rats). Brain Res., 112: 429-434.

Wilson, J. R., Wilson, L. M., and Dicara, L. V. (1977) Evidence for an elevation in thermoregulatory set-point in the SHR. Proc. 2nd Int. Sym. on SHR, DHEW Publ., No. (NIH) 77-1179, pp. 477-485.

WRIGHT, G. L. and KNECHT, E. (1977) Prediction of survival time of rats in hot environments. Ohio J. Sci., 77: 199-206.

YAMORI, Y., LovenBerg, W., and SJoerdsmA, A. (1970) Norepinephrine metabolism in brainstem of spontaneously hypertensive rats. Science, 170: 544-546. 